\title{
A Multi Criteria Approach to Rank Renewable Energy Technologies for Domestic Sector Electricity Demand of Pakistan
}

\author{
LEEZNA SALEEM*, AND INTIKHAB ULFAT* \\ RECEIVED ON 13.03.2018 ACCEPTED ON 25.05.2018 \\ ABSTRACT
}

\begin{abstract}
Renewable technologies could be utilized to solve the energy crises of world's sixth most populous country, Pakistan. Being rich in renewable resources of energy, the demand of electricity in household sector of Pakistan can easily be fulfilled which is otherwise scarce and have made the life of common people highly miserable. To formulate proper policies concerning the development of alternate energy sector it is essential to evaluate and prioritize the renewable technologies. In the present paper the aforementioned issue of evaluation and prioritization of renewable technologies has been addressed using AHP (Analytical Hierarchy Process) with the aim that the financial, technical, societal and environmental aspects are not compromised. Six alternatives (namely solar, wind, biomass, geothermal, ocean and hydel energies) have been prioritized. It has been concluded that to get around the crises of domestic electricity shortfall the choice of solar energy technology is the best among the alternatives highlighted above, followed by wind and biomass. With reference priority of the choice of alternate energy it is also emphasized that the financial aspect must be the decisive factor.
\end{abstract}

Key Words: Renewable Energy Technologies, Analytic Hierarchy Process, Electricity Crises, Domestic Sector, Pakistan.

\section{INTRODUCTION}

$\mathrm{P}$ akistan is a South Asian country with population of 208 million except Azad Kashmir and Gilgit Baltistan according to census of 2017 [1]. The world population is 7.6 billion [2] and Pakistan is the world's sixth most populous country. The population of Pakistan has increased by $57 \%$ since 1998 and $146.6 \%$ since 1981. The population of 10 major cities of Pakistan increased by $74 \%$. The average annual population growth rate is $2.4 \%$ (1998-2017) [1]. Pakistan has a total energy consumption of 75 million TOE. The domestic sector consumes $23 \%$ of the total energy in (2015-2016) compared to $22.5 \%$ in $2010-2011$. The energy consumption of the domestic sector contributes $1 \%$ oil, $60 \%$ gas, $5 \%$ LPG (Liquefied Petroleum Gas) and 34\% electricity in 20152016 [3]. The electricity consumed by the domestic sector of Pakistan has increased drastically during the last 10 years because of high population growth but the supplies are limited which result in the wide demand-supply gap 
of $7000 \mathrm{MW}$ in 2017 [4] compared to 4500MW in 2008 [5]. The fossil fuel reserves are decreasing which results in the rise of electricity prices and electricity shortages. Depleting energy resources is one the key reason for the energy shortages. Dependence on dwindling fossil fuel is making the crises more and more intense. Many areas of Pakistan are experiencing 12 hours of load shedding of electricity. This is making the lives of common people very difficult especially in hot summers. The government is importing LNG (Liquefied Natural Gas) which is added to the supply chain but this has not resolved the severe issue of shortages of house hold electricity supply till now. The world around us is transiting towards green energy to fulfill their energy needs. Renewable energy sources are considered the solution for the energy shortages due to the depletion of fossil fuel worldwide. [6]. It is projected that the world energy consumption will increase 28\% during 2015 and 2040. The non-fossil fuel consumption is expected to grow at a faster pace than fossil fuel[7].

\section{RENEWABLEENERGYRESOURCESOF PAKISTAN}

Pakistan has a rich resource of renewable energy. These renewable resources include Solar, Wind, Hydro, Biomass, Geothermal and Ocean energy [8]. To promote the development and deployment of renewable energy projects in Pakistan, two departments AEDB (Alternate Energy Development Board) and PCRET (Pakistan Council of Renewable Energy Technologies) are functionary under Govt. supervision. The share of renewable energy is less than $1 \%$ in total energy mix of Pakistan in 2015-2016 [3]. Some hydro projects are working in the country but the expansion of hydel projects is also facing challenges. There is a big margin of exploitations of renewable energy technologies in Pakistan. The brief resource potential of the six renewable energy technologies mentioned earlier are discussed in the following section.

\subsection{Solar Energy}

Pakistan has a huge potential of solar energy [9]. Pakistan receives sun shine more the 300 days/year. In various parts of the country the sun shine hours are around 7-8 hours/day [10]. Pakistan is situated in an area of highest solar average insolation in the world. Solar insolation of

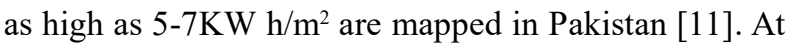
present various solar projects are in development phase under AEDB.

\section{$2.2 \quad$ Wind Energy}

In 2016 the installed electricity generation capacity from wind power increase by $12.5 \%$ compared to 2015 globally [12]. Our neighboring countries China and India have installed wind power capacity of 168690 and $28665 \mathrm{MW}$ respectively in 2017. In 2016 China and India has set new records for the wind energy growth [13]. Pakistan has an estimated potential of 50,000MW of wind energy. The average wind speed is more than $7 \mathrm{~m} / \mathrm{s}$ at $80 \mathrm{~m}$ height in most coastal areas of the country [14]. The coastal regions and various other regions have good potential for generating electricity from wind in Pakistan [15].

\subsection{Hydro Energy}

Pakistan has an estimated hydel power potential of 60,000 MW. Pakistan has an installed capacity of about 6720 MW of hydro power [16]. There is a lot of potential of hydroelectricity generation which could be explored if suitable policy and projects are implemented keeping aside false arguments. Micro hydel projects are considered a good approach to electrify rural households [17]. 


\subsection{Biomass}

Pakistan is an agriculture country. Biomass is an energy resource for Pakistan. Crops residues and animal dung are the biomass produced from agriculture and livestock [9]. Dispose of Municipal solid waste is a big issue faced by large cities in Pakistan, use of this waste to generate electricity could contribute to house hold sector electricity crisis. In villages waste from agriculture sector and livestock could be used to generate electricity.

\subsection{Ocean Energy}

Tidal power has an advantage on the other renewable resources as it is almost perfectly estimated for long time [18]. The coastal line of Pakistan extends about $1000 \mathrm{~km}$ with complex network of creeks in the Indus Delta region. The creek system of Indus Delta range over an area of $190 \mathrm{~km}^{2}$ [19]. Tidal power of Pakistan is not yet estimated and exploited. It could be a great potential source of energy to fulfill future energy needs of the country.

\subsection{Geothermal Energy}

The potential of geothermal energy for Pakistan has not been evaluated and exploited yet. It is present in the form of Hydro thermal resource and hot dry rocks. HVAC (Heating, Ventilation and Air Conditioning) and process heat are the major consumption unit of domestic sector and shallow geo thermal energy can provide the demand effectively [20].

\section{NEED OF EVALUATION AND PRIORITIZATION OF RENEWABLE ENERGY RESOURCES}

Diverse renewable energy sources should be used to attain a secure energy future. There is no debate for the issue that Pakistan is rich in renewable resources. Prioritization of renewable energy resources could help the government to formulate policy directions to develop a proper road map for the development of renewable energy sector. This is a complex issue; it must consider different perspective that are affecting our choices of renewable technologies. These perspectives are unique for different countries hence multi perspective analysis of renewable technologies is required. Literature review revealed that for the case of Pakistan the prioritization of the six renewable technologies for domestic sector electricity needs using AHP has not been done before. A research study was done in 2011 in which multi criteria decision model was used to evaluate the three renewable technologies solar, wind and biomass for the electricity generation in Pakistan [21]. Our scope of the study covers electricity generation for household sector of Pakistan with six renewable energy options. Our results differ from aforementioned study as they have not considered the hydel, ocean and geothermal technologies in their study and there is adequate more development in the field of alternate energy sources during the last decade that effects the results significantly. Evaluation and selection of renewable energy technologies in China was done in 2014 . They suggest that wind power is the best renewable energy source followed by solar photovoltaic, biomass, hydro, ocean and geothermal for the case of China. In their paper, they have developed a comprehensive evaluation index system using AHP and DAE (Data Envelopment Analysis). China is a leader in advancement of renewables worldwide and its progress could be a road map for other developing countries like Pakistan [22]. 


\section{METHODOLOGY}

In our research study, we have used MCDM (Multi Criteria Decision Making) for ranking of renewable technologies for domestic sector electricity needs of Pakistan. Renewable technologies could be used for many purposes including electricity generation, cooking, distillation and transportation but we have analyzed the resources for electricity generation.

\subsection{Multi-Criteria Decision Analysis}

MCDA (Multi-Criteria Decision Analysis) is used in various disciplines for example making decisions in health care, defense, environment, investment, education and energy resources. It considers multiple actors, criteria and objective MCD models are extensively used as evaluation technique in renewable energy sector. They provide the researcher flexibility of considering the objective and criteria at the same time. These models used two approaches direct approach and indirect approach. In direct approach priorities or weights are assigned due to inputs from beneficiary and society based on survey. In indirect approach, all the possible criteria are further characterized into sub criteria and then assigned priorities as per previous problems, judgment of decision maker based on experience and data analysis etc.[23].

\subsection{Analytical Hierarchy Process}

One of the methods used for MCDM is AHP. AHP is extensively used in energy planning as well as resource management. AHP was originally developed by Saaty. The working steps for this method are:

(i) Description of objectives into a hierarchical model. (ii) Determination of weights for each criterion.

(iii) Calculating priorities of each alternative in the view of criteria.

(iv) Calculating overall priority.

The model has following strength

(i) It is adaptable.

(ii) It is simple and complex mathematics is not involved.

(iii) As the model is based on hierarchical structure each criterion could be better judged and analyzed transparently [24].

AHP was used to prioritize utilization of solar energy technologies in Jordan [25]. Wind energy and clean coal technologies was evaluated and prioritize for the Pacific. North West AHP was used for the evaluation [26]. Literature review proved the existence of evaluation and selection. For the development of sustainable supply chain supplier selection is an important aspect [27]. This paper review 36 journal article on green suppliers, evaluation and selection of renewable supplies. It has been evaluated that $16.6 \%$ of the journal articles reviewed propose AHP for green supplier selection. AHP based on expert's feedback was used to prioritize Algerian energy sources. The criteria were further divided into 13 sub-criteria. The study results show that solar is the best suitable energy technology for Algeria [28]. The classification of renewable energy alternative is done for the state of Crete using multi-criteria method [29].

The evaluation of the potential of offshore wind energy was done using AHP for Taiwan [30]. 


\subsection{Evaluation of Index System for Renewable Energy Technologies of Pakistan}

For the analysis and prioritization of renewable energy technologies for Pakistan we have selected four indexes or criteria. The indexes are financial, technical, societal and environmental. The factors influencing the indexes are shown in Fig. 1. Financial index is dependent on deployment and maintenance cost and production capacity, equipment performance time and output power capacity are important technical factors. Societal index is dependent on land area utilization, acceptance of a particular technology from the society and the number of jobs created as a result of deployment of the project. Pakistan is facing a high unemployment rate hence creation of jobs is an important factor. From environmental index $\mathrm{CO}_{2}$ and $\mathrm{SO}_{2}$ emission and impact on ecosystem are considered. Model is developed using Delphi technique with four criteria and eleven indicators.

\subsection{Methodological Approach}

To evaluate Renewable Energy Technologies for Pakistan a research approach has been designed with the formulation of AHP model and evaluation of expert's feedback. Ten energy experts were selected with expertise in renewable energy and energy policy. The experts belong to both academic and industrial sector. Experts were informed about the objective of the study. The judgement from the experts were collected through face to face interviews. The experts were asked to give their judgement on pairwise comparison of criteria that aim to provide the vector of weights that represent the priority each expert assigned to each criterion. In the next step the experts were requested to assign the priority regarding the performance of alternatives with respect to each criterion to generate normalize matrix of options. The final ranking of renewable energy technologies is done by combining the vector of weight of criteria and normalize matrix of options. The pair wise comparison was done according to preference scale shown in Fig. 2.

Following are the sequential steps followed by the study:

(a) Objective statement and formulation of hierarchy problem.

(b) Pair wise comparison of criteria and computation of normalize vector of criteria weights.

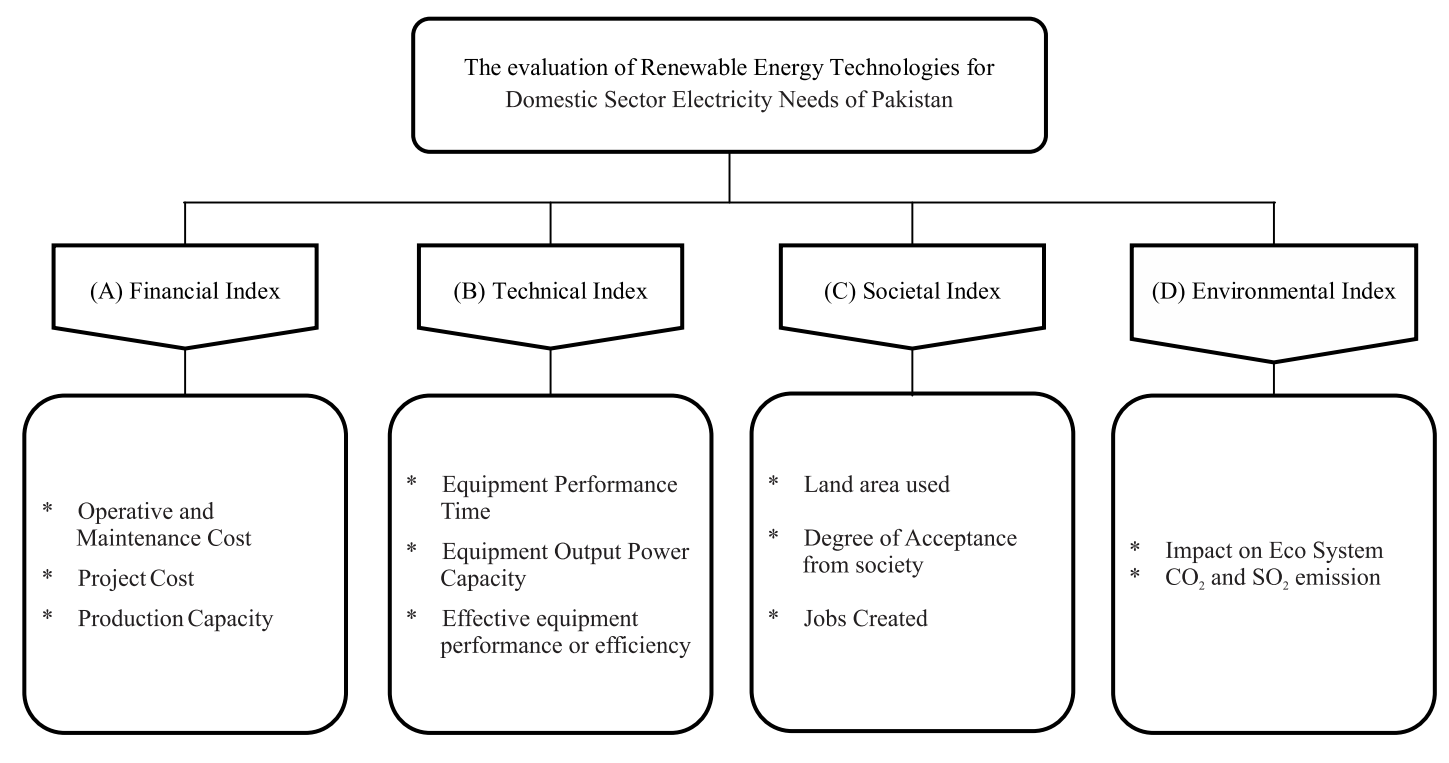

FIG. 1. INDEX SYSTEM FOR EVALUATION OF RENEWABLE TECHNOLOGIES FOR PAKISTAN 
(c) Pair wise comparison of alternatives with respect to each criterion and computation of normalize matrix for alternative.

(d) Consistency checking of decision and if found in consistent the procedure was repeated.

(e) By the combination of step (b) and (c) the priority weights of alternatives are calculated and the final ranking was done.

The AHP method is applied in an excel file for the computation of scores, consistency checking and ranking of alternatives.

\section{ANALYSIS OF DATAAND RESULTS}

The priority weights for the indexes are calculated by formulating a paired matrix. The composite weights of each renewable technology are calculated. The ranking of renewable technologies was done according to weights. The AHP process was applied and following criteria weights are obtained as shown in Table 1.

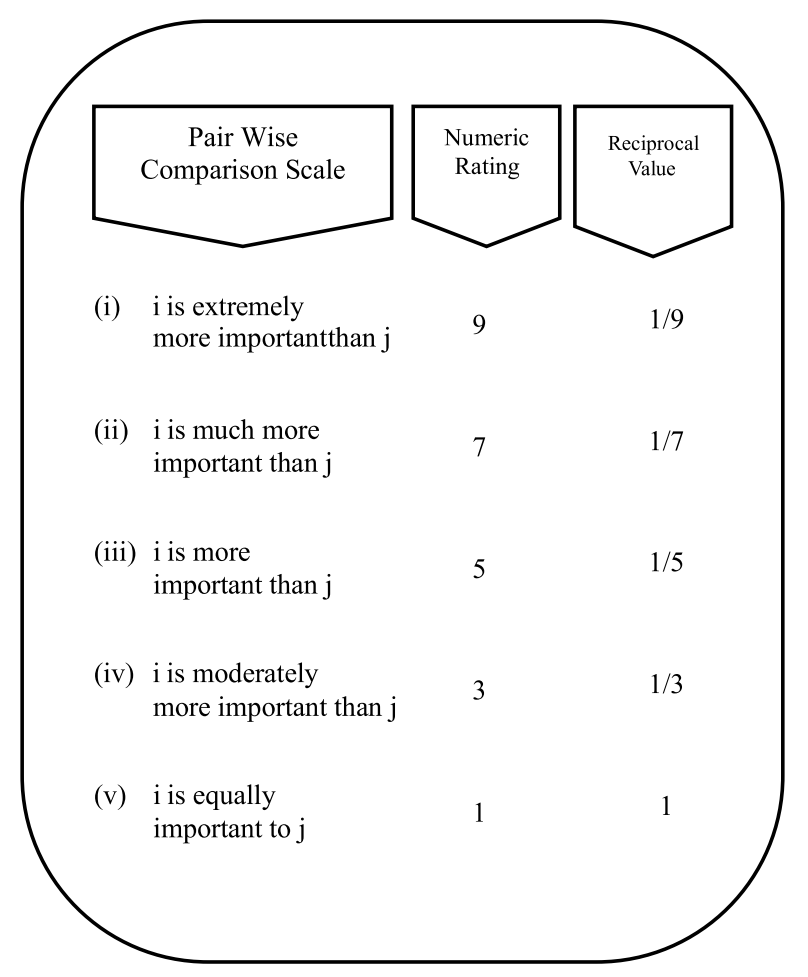

FIG. 2. PREFERENCE SCALE FOR PAIR WISE COMPARISON
Financial criteria gained the priority with relative weight of 0.57 . Technical stood at the second rank with relative weight of 0.29 . Societal and environmental criteria got third and fourth priority consecutively. The economy of Pakistan is facing severe crises. Majority of population comes under low income group. The technology which is cheaper is more suitable for domestic electricity generation. For adoption of a technology it should be technically mature with greater equipment performance time and output power capacity. Pakistan has a high unemployment rate creation of jobs is an important aspect. The society should benefit from the technology. Large cities in Pakistan are already facing health hazards from polluted environment. The technology with less $\mathrm{CO}_{2}$ and $\mathrm{SO}_{2}$ emission should be given priority. The priority weight of alternative with respect to financial criteria is shown in Table 2 .

Solar has gained relative weight of 0.40 in financial index. The prices of solar modules have decreased significantly in the previous decade. Wind and solar attain $65 \%$ of the total priority in financial criteria. Biomass stood at third rank followed by hydro, ocean and geothermal. The priority weights of alternatives with respect to technical criterion are shown in Table 3.

Solar gained the highest priority weight in technical criteria followed by wind. The efficiency of solar modules has risen with its increased use worldwide. Solar has become more technically mature. Some experts are skeptical concerning the maturity of wind technology. Hydro also performed well in technical criteria. Pakistan

TABLE 1. PRIORITY WEIGHTS OF CRITERIA WITH RESPECT TO GOAL

\begin{tabular}{|c|c|c|}
\hline & Relative Weights & Relative Impact (\%) \\
\hline Financial & 0.57 & 57.39 \\
\hline Technical & 0.29 & 29.13 \\
\hline Societal & 0.09 & 9.03 \\
\hline Environmental & 0.05 & 4.45 \\
\hline
\end{tabular}

Mehran University Research Journal of Engineering \& Technology, Volume 38, No. 2, April, 2019 [p-ISSN: 0254-7821, e-ISSN: 2413-7219] 
has an experience of generating electricity from hydel resource historically. With the expected increase in the use of ocean energy worldwide it is also expected to gain more technical maturity. The priority weight of alternatives with respect to societal criteria is shown in Table 4.

Solar gained the highest priority as it is already gaining popularity among masses for electricity generation. Wind stood second in societal criteria but with relatively low performance than in other criteria. Hydro has gained a relative weight of 0.14 . It performed better in societal criteria

TABLE 2. PRIORITY WEIGHT OF ALTERNATIVE FOR CRITERIA-A

\begin{tabular}{|c|c|}
\hline & Relative Weights \\
\hline Solar & 0.40 \\
\hline Wind & 0.25 \\
\hline Hydro & 0.10 \\
\hline Ocean & 0.06 \\
\hline Biomass & 0.16 \\
\hline Geothermal & 0.03 \\
\hline
\end{tabular}

TABLE 3. PRIORITY WEIGHT OF ALTERNATIVE FOR CRITERIA-B

\begin{tabular}{|c|c|}
\hline & Relative Weights \\
\hline Solar & 0.45 \\
\hline Wind & 0.21 \\
\hline Hydro & 0.09 \\
\hline Ocean & 0.07 \\
\hline Biomass & 0.15 \\
\hline Geothermal & 0.03 \\
\hline
\end{tabular}

TABLE 4. PRIORITY WEIGHT ALTERNATIVE FOR CRITERIA-C

\begin{tabular}{|c|c|}
\hline & Relative Weights \\
\hline Solar & 0.47 \\
\hline Wind & 0.20 \\
\hline Hydro & 0.14 \\
\hline Ocean & 0.06 \\
\hline Biomass & 0.09 \\
\hline Geothermal & 0.04 \\
\hline
\end{tabular}

as society gains benefits from hydel dams. Pakistan is an agricultural country and availably of water for domestic and agricultural needs is important. Table 5 shows priority weights of alternatives with respect to environmental criteria.

Wind, ocean and hydro gained a cumulative priority of 0.55 in this criterion. Wind has gained second highest priority with hydro and ocean also performing well. Biomass gained the lowest relative weight. Aggregate priorities of the alternatives with respect to the goal is shown in Table 6.

Solar stood at first rank with priority weight of 0.42 . Wind is ranked second followed by biomass, hydro, ocean and geothermal energies. Solar and wind has gained importance in almost all the criteria. In financial criteria biomass has also gained better priority as biomass plants on small scale in remote villages are

TABLE 5. PRIORITY WEIGHT OF ALTERNATIVE FOR CRITERIA-D

\begin{tabular}{|c|c|}
\hline & Relative Weights \\
\hline Solar & 0.37 \\
\hline Wind & 0.28 \\
\hline Hydro & 0.15 \\
\hline Ocean & 0.12 \\
\hline Biomass & 0.03 \\
\hline Geothermal & 0.05 \\
\hline
\end{tabular}

TABLE 6. AGGREGATE PRIORITY WEIGHTS OF EACH ALTERNATIVE WITH RESPECT TO GOAL

\begin{tabular}{|c|c|c|}
\hline & PriorityWeights & Ranking \\
\hline Solar & 0.42 & 1 \\
\hline Wind & 0.24 & 2 \\
\hline Hydro & 0.10 & 4 \\
\hline Ocean & 0.06 & 3 \\
\hline Biomass & 0.15 & 6 \\
\hline Geothermal & 0.03 & 5 \\
\hline
\end{tabular}

Mehran University Research Journal of Engineering \& Technology, Volume 38, No. 2, April, 2019 [p-ISSN: 0254-7821, e-ISSN: 2413-7219] 
feasible financially. Hydel also gained 0.10 priority weight as micro hydel projects are recognized among energy specialist as good opportunity for generating electricity which could be used to supply electricity especially to rural households. Society is inclined towards solar and wind. Hydro also performed well in societal index. Wind and ocean energy has performed exceptionally well in environmental criteria. Biomass has gained the lowest priority in environmental criterion.

\section{CONCLUSION}

Our study concludes that renewable technology which is less expensive and technically mature in nature is the priority. The results further conclude that solar is the preferred renewable technology source for Pakistan, wind stood at second rank followed by biomass hydro, tidal and geothermal. Solar could be the solution to resolve electricity crises faced by domestic sector of Pakistan. Rural as well as urban area could be facilitated by possible this technology. It could light up lives of people in villages where resources are limited. Diversification in the use of renewable sources is also identified as crucial according to our study to attain energy security for Pakistan. All available renewable resources should be exploited to attain sustainable energy future for the country. National renewable energy planning should be done using the decision models that use multi criteria for the selection of renewable technologies to attain success full transition towards renewables for energy.Proper policy direction should be taken by the government to lead the country toward a proper road map to attain secure energy future by the development of renewable energy sector. This could significantly help in improving living standards of society, environmental sustainability and reduction of electricity shortage in domestic sector. AHP is identified as suitable method to take decisions regarding renewable energy technologies. Our hierarchical model could be applied to study the renewable energy resources of other regional countries as well.

\section{ACKNOWLEDGMENTS}

The authors are thankful to the anonymous referees for their useful suggestions that led us to improve the quality of the paper. The author also acknowledgment the cooperation of the Department of Physics, University of Karachi, and Education and Literacy Department, Govt. of Sindh, Pakistan, during the study.

\section{REFERENCES}

[1] Provisional Summary Results of $6^{\text {th }}$ Population and Housing Census-2017, Pakistan Bureau of Statistics. [online] Available at: http://www.pbs.gov.pk/content/ provisional-summary-results-6th-population-andhousing-census-2017 [Accessed 21 January, 2018].

[2] United Nation Population Division "World Population Prospects", 2017. [online]Available at: https:// www.un.org/development/desa/publications/worldpopulation-prospects-the-2017-revision.html [Accessed 21 January, 2018].

[3] HDIP, "Pakistan Energy Year Book, 2016", Ministry of Energy (Petroleum Division), Hydrocarbon Development Institute of Pakistan, 2017.

[4] Kiani, K., "PowerCuts Return as Shortfall Touches 7,000MW”, 2017 [online] DAWN.COM. Available at: https://www.dawn.com/news/1331738 [Accessed 21 January, 2018]

[5] Asif, M., "Sustainable Energy Options for Pakistan", Renewable and Sustainable Energy Reviews, Volume 13, No. 4, pp.903-909,2009.

[6] Jefferson, M., "Sustainable Energy Development: Performance and Prospects", Renewable Energy, Volume 31, No. 5, pp. 571-582, 2006. 
[7] EIA, "Today in Energy", Energy Information Administration, US Department of Energy, 2017 [online]Available at: https://www.eia.gov/todayinenergy/ index.php?tg=renewables [Accessed 21 January, 2018].

Wakeel, M., Chen, B., and Jahangir, S., "Overview of Energy Portfolio in Pakistan”, Energy Procedia, Volume 88, pp. 71-75, 2016.

Chaudhry, M.A., Raza, R., and Hayat, S., "Renewable Energy Technologies in Pakistan: Prospects and Challenges", Renewable and Sustainable Energy Reviews, Volume 13, No. 6-7, pp.1657-1662, 2009.

[10] Sheikh, M., "Energy and Renewable Energy Scenario of Pakistan", Renewable and Sustainable Energy Reviews, Volume 14, No. 1, pp.354-363,2010.

[11] NREL, "Solar Map of Pakistan", US National Renewable Energy Laboratory, 2017[online]Available at: https:// www.nrel.gov/renewable_resources/ [Accessed 21 January, 2018].

[12] GWEC, "Global Wind Report Annual Market Update”,2017[online] Available at:http://gwec.net/ publications/global-wind-report-2/[Accessed 21 January, 2018].

[13] GWEC, "Global Wind Energy Statistics", 2016 [online] Available at:www.gwec.net/wpcontent/uploads/vip/ GWEC_PRstats2016_EN_WEB.pdf [Accessed 21 January, 2018].

[14] Ghayur, A., "Role of Satellite for Renewable Energy Generation Technology in Urban Regions and Urban Settings", International Conference on Advances in Space Technologies, Institute of Electrical Engineering Computer Society, Islamabad, Pakistan, 2006.

[15] Mirza, I., Khan, N., and Memon, N., "Development of Benchmark Wind Speed for Gharoand Jhimpir, Pakistan", Renewable Energy, Volume 35, No. 3, pp. 576-582, 2010.

[16] Balkhair, K., and Rahman, K., "Sustainable and Economical Small-Scale and Low-Head Hydropower Generation: A Promising Alternative Potential Solution for Energy Generation at Local and Regional Scale", Applied Energy, Volume 188, pp. 378-391, 2017.
[17] PPIB, "Hydro Power Resource of Pakistan", Private Power and Infrastructure Board, Islamabad, Pakistan, 2010 [online] Available at:http://www.ppib.gov.pk/ [Accessed 21 January, 2018].

[18] Baig, M., Uddin, Z., and Insaf, A., “An Initial Tidal Power Resource Estimation at Jhari Creek of Indus Delta, Sindh, Pakistan”, Journal of Basic \& Applied Sciences, Volume 13, pp. 545-550, 2017.

[19] Mahar, G.A., and Zaigham, N.A., "Identification of Climate Changes the Lower Indus Basin Sindh", Pakistan Journal of Basic and Applied Sciences, Volume 6, No. 2, 2010

[20] Gondal, I., Masood, S., and Amjad, M., "Review of Geothermal Energy Development Efforts in Pakistan and Way Forward", Renewable and Sustainable Energy Reviews, Volume 71, pp.687-696,2017.

[21] Amer, M., and Daim, T., "Selection of Renewable Energy Technologies for a Developing Country: A Case of Pakistan", Energy for Sustainable Development, Volume 15, No. 4, pp. 420-435, 2011.

[22] Li-bo, Z., and Tao, Y., "The Evaluation and Selection of Renewable Energy Technologies in China”, Energy Procedia, Volume 61, pp. 2554-2557, 2014.

[23] Wimmler, C., Hejazi, G., Fernandes, O.E., Moreira, C., and Connors, S., "Multi-Criteria Decision Support Methods for Renewable Energy Systems on Islands", Journal of Clean Energy Technologies, Volume 3, pp. 185-195, 2015.

[24] Saaty, T.L., "The Analytical Hierarchy Process: Planning Priority Settings Resource Allocation”, Decision Making Series, McGraw Hill, New York, USA, 1980.

[25] Elkarmi, F., and Mustafa, I., "Increasing the Utilization of Solar Energy Technologies in Jordan”, Energy Policy, Volume 21, No. 9, pp. 978-984, 1993.

[26] Diam, T., Yates, D., and Jimenez, B., “Technology Assessment for Clean Energy Technologies the Case of Pacific North-West", Technology Society, Volume 31, pp. 232-43, 2009. 
[27] Govindan, K., Rajendran, S., Sarkis, J., and Murugesan, P., "Multi Criteria Decision Making Approaches for Green Supplier Evaluation and Selection: A Literature Review", Journal of Cleaner Production, Volume 98, pp. $66-83,2015$.

[28] Haddad, B., Liazid, A., and Ferreira, P., "A Multi-Criteria Approach to Rank Renewables for the Algerian Electricity System", Renewable Energy, Volume 107, pp. 462-472, 2017.
Tsoutsos, T., Drandaki, M., Frantzeskaki, N., Iosifidis, E., and Kiosses, I., "Sustainable Energy Planning by Using Multi-Criteria Analysis Application in the Island of Crete", Energy Policy, Volume 37, No. 5, pp. 1587-1600, 2009 .

[30] Lee, T., "Assessment of the Potential of Offshore Wind Energy in Taiwan Using Fuzzy Analytic Hierarchy Process", The Open Civil Engineering Journal, Volume 4, No. 1, pp. 96-104, 2013. 